\title{
Fault Section Estimation in Radial LVDC Distribution System Using Wavelet Transform ${ }^{\dagger}$
}

\author{
Hun-Chul Seo ${ }^{1, *(D)}$, Gi-Hyeon Gwon ${ }^{2}$ and Keon-Woo Park ${ }^{3}$ \\ 1 Department of Electrical \& Electronic Engineering, Yonam Institute of Technology, Jinju-si 52821, Korea \\ 2 Department of Smart Electrical \& Electronic Engineering, Yonam Institute of Technology, Jinju-si 52821, Korea; \\ gwongh@yc.ac.kr \\ 3 Next Square, Gunpo-si 15850, Korea; nsdap@naver.com \\ * Correspondence: hunchul0119@hanmail.net \\ + The present work is an extension of the paper "Fault Section Estimation in LVDC Distribution System" \\ presented to APAP 2021 Conference, Jeju, Korea, 11-14 October 2021.
}

Citation: Seo, H.-C.; Gwon, G.-H.; Park, K.-W. Fault Section Estimation in Radial LVDC Distribution System Using Wavelet Transform. Energies 2021, 14, 8486. https://doi.org/ $10.3390 /$ en 14248486

Academic Editor: Abu-Siada Ahmed

Received: 15 November 2021 Accepted: 14 December 2021 Published: 16 December 2021

Publisher's Note: MDPI stays neutral with regard to jurisdictional claims in published maps and institutional affiliations.

Copyright: (c) 2021 by the authors. Licensee MDPI, Basel, Switzerland. This article is an open access article distributed under the terms and conditions of the Creative Commons Attribution (CC BY) license (https:// creativecommons.org/licenses/by/ $4.0 /)$.

\begin{abstract}
The demand for low voltage DC (LVDC) distribution systems is increasing due to the rapid development of power conversion technology, the increase of DC-based digital loads, and the expansion of DC-based distributed generation (DG). For the stable operation of the LVDC distribution system, it is necessary to develop a protection method. In this paper, the fault section is estimated using wavelet transform (WT) in LVDC distribution system. The fault section is classified into a DC line and a DC bus. The characteristics of fault current at each fault section part are analyzed in simple and actual LVDC system. Based on this analysis, the algorithm for fault section estimation is proposed using the detail component after performing WT. The results of fault section estimations are verified through various simulations using EMTP and MATLAB. The fault section estimation can be utilized in the development of protection schemes in LVDC distribution system.
\end{abstract}

Keywords: fault current; fault section estimation; LVDC distribution system; wavelet transform

\section{Introduction}

The DC power supply method reduces power losses through high efficiency conversion that reduces the number of AC/DC power conversions, which can be a very effective countermeasure at a time when global warming is urgently needed. Therefore, it is necessary to improve energy efficiency and power quality and to increase system reliability by developing the protection technology for the transient state in the LVDC distribution system [1].

Various studies on protection have been conducted in LVDC distribution systems. In [2], a method for fast dc fault detection and interruption was proposed using advanced local measurements and communications available in the smart grid. In [3], a method to detect and locate LVDC faults was proposed using several intelligent relays based on DC current direction and combined with controllable solid-state circuit breakers. In [4], a mathematical morphology-based protection method was proposed using the features from fault currents with capacitor discharge characteristics or high impedance faults with arcing phenomenon. In [5], a mathematical model for describing fault energy during the transient period of LVDC faults was developed; this paper proposed a new fault letthrough energy based LVDC fault location. In [6], a noniterative fault location technique using a probe power unit was proposed in the LVDC microgrid system. In [7], a novel local measurement-based fault location algorithm was proposed for tightly coupled LVDC distribution systems. In [8], analytical methods and signal processing methods for fault location were proposed in LVDC network. In [9], a new protection method for LVDC ring-bus microgrid systems based on Multi-Criterion System and Neural Network (NN) were proposed. In [9], NN was used to estimate the fault location as a percentage of line 
length. In [10], the novel fault location method was proposed using the ability of short time Fourier transform in local signals analysis. In [11], the fault location was estimated by comparing an analytically derived fault current with the measured value of fault current. In [12], a theoretical analysis with fewer errors was used to develop protection schemes and short-circuit fault locations based on transient- and steady-state analytic formulas. In [13], DC fault characteristics were analyzed in LVDC network, which highlighted the worst case scenarios during a fault and protection related issues and proposed the protection schemes for the LVDC network. In [14], a better scheme for fault detection and a novel method for the fault location were proposed. In [15], a detection method of the pole to ground fault in ungrounded LVDC distribution grid was proposed using the discrete wavelet transform of measurement current by signal injection method. In [16], a fast and effective variational mode decomposition (VMD)-based fault detection technique was proposed for the LVDC distribution system with penetration of renewable sources using the local end current measurements only. For the stable operation of the LVDC distribution system, it is necessary to estimate the fault section and apply the appropriate protection method. However, previous studies on the fault section have not been performed.

Wavelet transform (WT) is a mathematical method widely used in various fields, such as signal and image processing. The WT can be used in a wide range rather than a specific frequency domain. WT has been widely used for power system transient analysis and protection. The WT has been variously applied in the alternating current (AC) transmission and distribution system [17-19]. Therefore, WT can be applied to the protection in LVDC microgrid.

The new contribution of this paper is as follow:

(1) The characteristics of fault current are analyzed at various fault sections in the simple and actual complex LVDC distribution system;

(2) The algorithm for fault section estimation is proposed using the WT;

(3) The proposed scheme is verified by the various simulations in both the simple and actual LVDC distribution system.

In this paper, the method for fault section estimation using WT is proposed in a LVDC distribution system. In Section 2, the characteristics of the fault current in various fault sections of the LVDC distribution system are analyzed. In Section 3, the method for fault section estimation using WT is proposed based on the analysis in Section 2. In Section 4, various simulations are performed to verify the algorithm proposed in this paper. Section 5 presents the conclusion of this paper.

\section{Characteristics of Fault Current at LVDC Distribution System}

Figure 1 shows a simple LVDC distribution system. It consists of an AC/DC converter to connect to the AC side, LVDC distribution lines, LVDC bus, loads, DC/DC converter connected to the load, and circuit breaker (CB). This paper considers the LVDC distribution system as an ungrounded system. The fault type of LVDC distribution system can be classified into the pole-to-pole fault and the pole-to-ground fault. In an ungrounded system, the detection of fault current at the pole-to-ground fault is difficult and hence this paper only considers the pole-to-pole fault. In Figure 1, each number represents a possible fault sections. The meaning of each number is as follows:

Fault section (1): Fault on the LVDC bus;

Fault section (2): Fault on the LVDC line.

Figure 2 compares the flows of currents at steady state and fault state when the fault occurs on the LVDC bus (fault section (1)). Under steady state, current flows to the load. However, in the fault state, the current in the opposite direction to the steady state will flow due to the discharge of the capacitor of the DC/DC converter connected to load. In addition, this current will flow through the LVDC distribution line. Figure 3 compares the current flow in the normal state and in the fault section (2). The capacitor discharge current of the DC/DC converter will flow to the fault point in the line, and the capacitor discharge 
current of the AC/DC converter will flow in the CB. Therefore, the direction of current flow in the $\mathrm{CB}$ is the same in the normal and fault states. Therefore, a current of the same polarity in the steady state will be measured in the $\mathrm{CB}$. Because the current by the capacitor discharge of $\mathrm{AC} / \mathrm{DC}$ converter will flow in the $\mathrm{CB}$, the direction of current flow is the same in the normal and fault states. Therefore, a current of the same polarity in the steady state will be measured. The current flow in Figure 3 depends on where the distribution line fault occurs. If a fault occurs in the distribution line at the $\mathrm{CB}$, the situation is too similar to that in Figure 2. However, this is very specific case and this paper does not consider this situation.

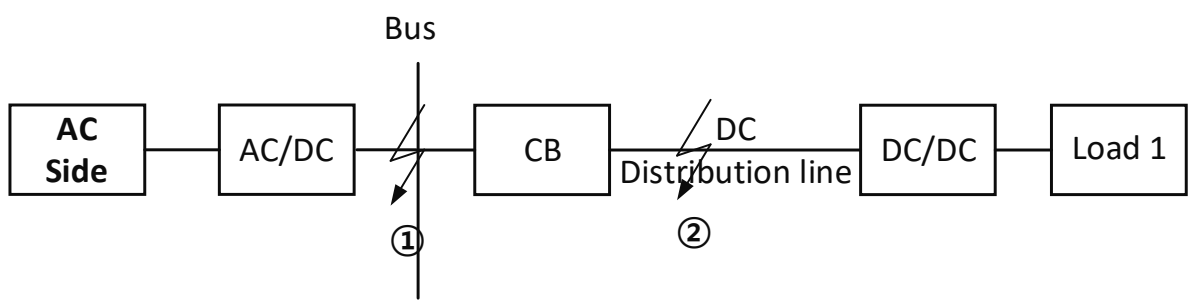

Figure 1. LVDC distribution system.

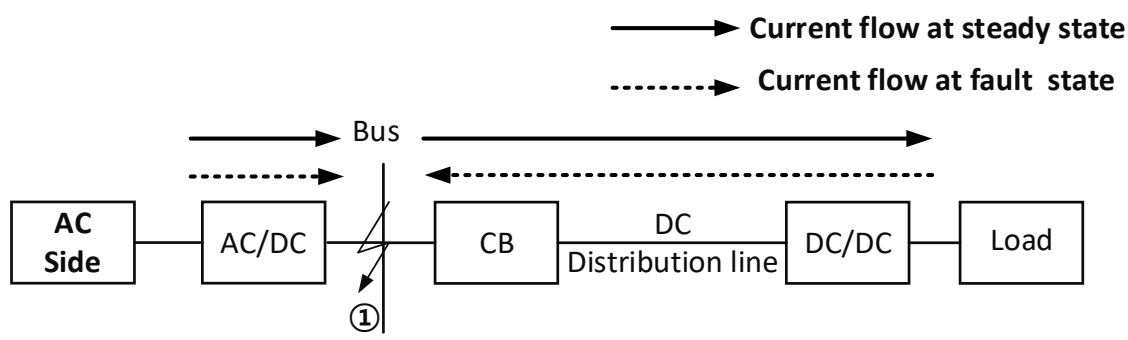

Figure 2. Fault current comparison at LVDC bus fault in simple LVDC system.

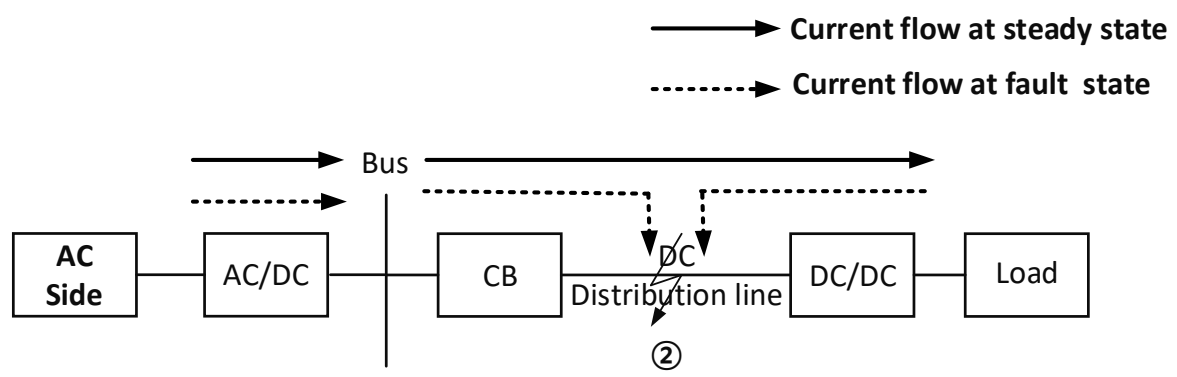

Figure 3. Fault current comparison at LVDC line fault in simple LVDC system.

Figures 2 and 3 analyze the characteristics of fault current in a simple LVDC distribution system. We extend the above analysis to the actual complex LVDC distribution system. The actual distribution line consists of multiple distribution lines and loads. As shown in Figure 4, in the event of a LVDC bus fault, the characteristics of fault current flowing in the $\mathrm{CB}$ are the same with the above analysis by reasons, such as the polarity of the current flowing through the $\mathrm{CB}$ is reversed and this current flows through the distribution line. Figure 5 shows the comparison of the current flow in the normal state and line fault state in actual LVDC distribution line. In case of LVDC line fault, the discharge current of capacitor in the $\mathrm{AC} / \mathrm{DC}$ converter will directly flow to the $\mathrm{CB}$ of the faulted distribution line. Additionally, the discharge current of the DC/DC capacitor in the healthy distribution line, rather than the faulted line, will be combined. That is, the point that the discharge current of capacitor in the AC/DC converter directly flows is the same with the above analysis. Therefore, even in an actual LVDC distribution system, the characteristics of the fault current flow are the same. 


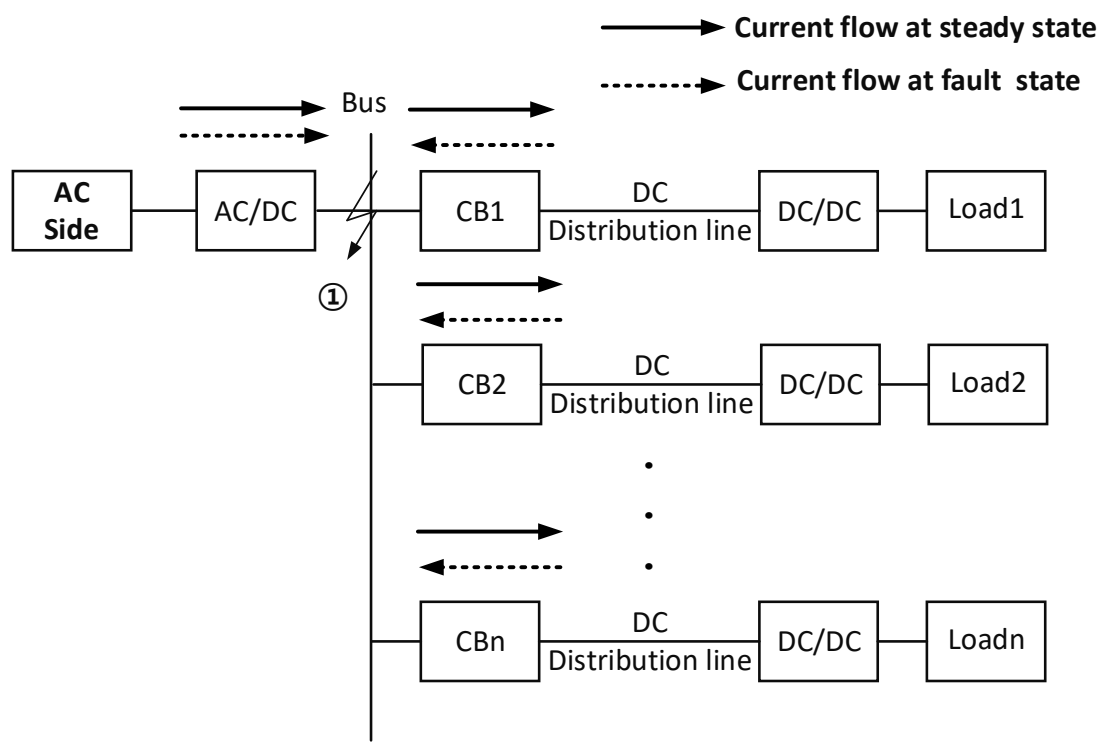

Figure 4. Fault current comparison at LVDC bus fault in actual LVDC system.

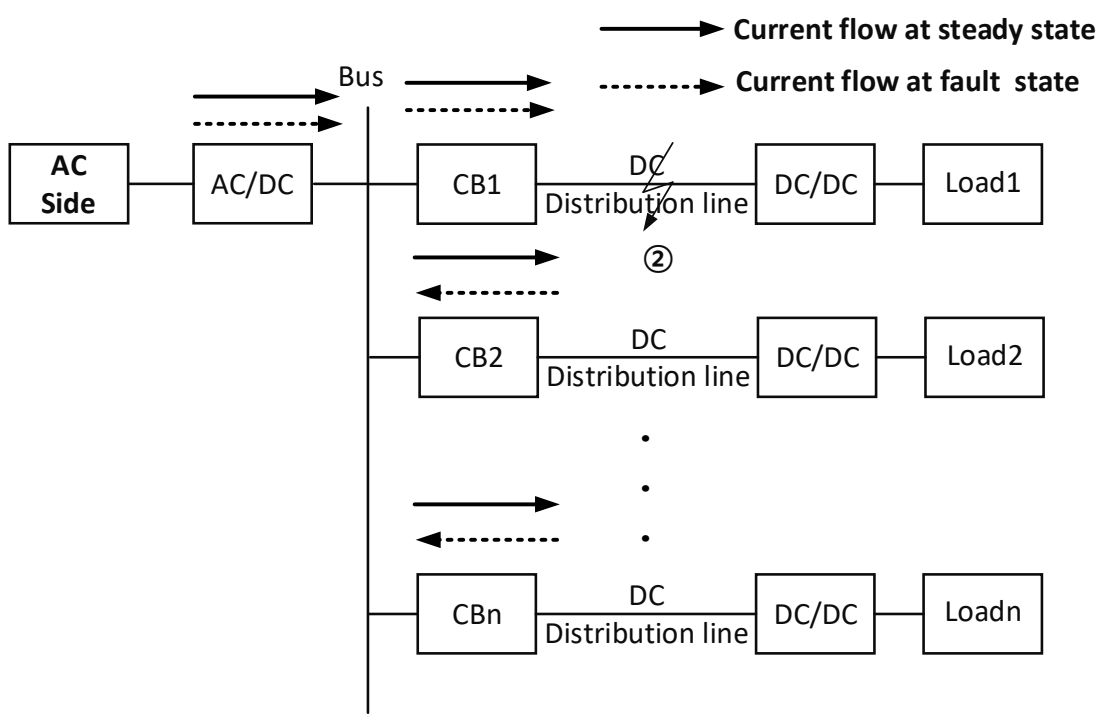

Figure 5. Fault current comparison at LVDC line fault in actual LVDC system.

The differences between the currents flowing in a bus fault and in the distribution line fault are analyzed. In both cases, the points that the discharge current of capacitor flows the same. However, in case of a distribution line fault, because it passes through the distribution line, attenuation of high-frequency components due to resistance and inductor components of the distribution line may appear. Therefore, it is expected that the harmonics and high-frequency components of the current flowing through the $\mathrm{CB}$ at LVDC line fault will be attenuated than that at the LVDC bus fault. In order to utilize these characteristics, this paper uses the WT to propose the algorithm for the fault section.

\section{Fault Section Estimation Using Wavelet Transform}

In this section, the method of fault section estimation in radial LVDC distribution system is proposed based on the analysis of Section 2. Figure 6 shows the proposed algorithm for fault section estimation in radial LVDC distribution system using WT. The proposed method first receives the currents (i) flowing through CB as input. The next step is to perform the WT using this current. 


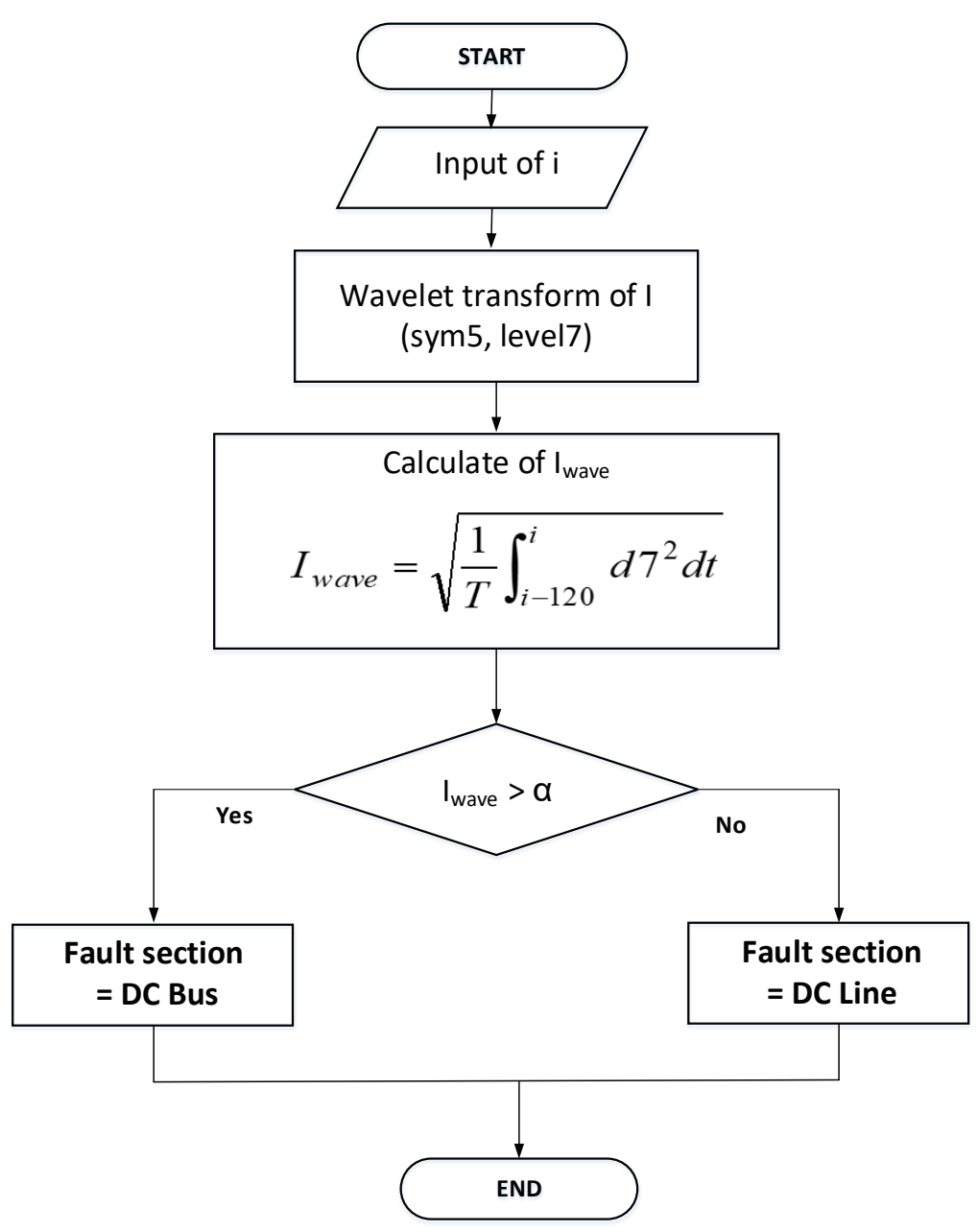

Figure 6. Algorithm of fault section estimation in radial LVDC distribution system.

A WT can extract time and frequency information simultaneously from an original signal [19]. The discrete wavelet transform (DWT) of a signal is defined as:

$$
\operatorname{DWT}(m, k)=\frac{1}{\sqrt{a_{0}^{m}}} \sum_{k=1}^{N} x(n) g\left(\frac{k-n a_{0}^{m} b_{0}}{a_{0}^{m}}\right)
$$

where $x(n)$ is the input signal, $g(n)$ is the mother wavelet, $a_{0}^{m}$ is a scale parameter, $n a_{0}^{m} b_{0}$ is the time shift of $g(n)$, and scaling parameter " $a$ " and translation parameter " $b$ " are functions of integer parameter $m$ [19].

There are various mother wavelets such as Haar, Daubechies $(\mathrm{db}) \mathrm{N}$, and Symlets $\mathrm{N}$ for WT. The mother wavelets are classified according to their length and properties. In signal processing, the WT can be obtained by scaling and moving the mother wavelet. Therefore, it is very important to select an appropriate mother wavelet. Among the various mother wavelets, sym 5 has been widely used for power system transients and protection [17-19]. Therefore, in this paper, the mother wavelet is also selected as sym5.

After performing the WT, the original signal decomposed to the detail $(D)$ component and approximation $(A)$ components. The detail component represents the high-frequency components of a signal and the approximation components represents the low-frequency components of a signal. The approximation can be decomposed many times with detail and approximation. In this process, the original signal $S$ can be represented as follows [19]:

$$
S=D 1+D 2+\cdots+D n+A n
$$


In this paper, Equation (3) is calculated using detail components, which are taken after performing WTs at levels 7 . In (3), $d 7$ are detail components after WTs. $T$ means the period (16.66 ms) based on $60 \mathrm{~Hz}$ of AC. This paper is based on the 120 samples/cycle. In (3), $i$ means the present sample and $i-120$ means the sample before 1 cycle. Equation (3) means the rms value of $d 7$ component:

$$
I_{\text {wave }}=\sqrt{\frac{1}{T} \int_{i-120}^{i} d 7^{2} d t}
$$

Because the calculation result of Equation (3) uses the detail components, the high frequency components will be included. In Section 2, we analyze the attenuation of the high-frequency components in LVDC line fault. Therefore, we can expect that the calculation value of Equation (3) in LVDC bus fault is larger than that in LVDC line fault. In the proposed algorithm of this paper, we utilize the result of this analysis. In the algorithm, $\alpha$ is a threshold value to distinguish the fault section. If it is larger than this value, it is judged as LVDC bus fault; if it is smaller than this value, it is judged as LVDC line fault.

\section{Simulations}

\subsection{Verification in Simple LVDC Sistribution System}

\subsubsection{System Model and Simulation Conditions}

The simple LVDC model to verify the proposed method is presented in Figure 1 . The length of the LVDC distribution line is $2 \mathrm{~km}$ and the DC load is $50 \mathrm{~kW}$. The pole-to-pole voltage at LVDC bus is $1500 \mathrm{~V}$ and the pole-to-pole voltage at load is $380 \mathrm{~V}$. The system model is implemented using EMTP. In EMTP modelling, the distribution lines are modelled using the lumped model built in the EMTP. The LVDC loads are modelled using the resistor. As discussed in Section 2, this paper considers the LVDC distribution system in Figure 1 as the ungrounded system. Therefore, in the modelling of EMTP, the positive and negative poles exist and the neutral line does not exist. The AC/DC converter uses a full-bridge converter topology based on the three-phase Sinusoidal Pulse Width Modulation (SPWM) method. It is designed to follow the output voltage of $1500 \mathrm{~V}$ using the PI controller. The DC/DC converter uses a PWM-based Buck Converter topology and is modelled to have an output voltage of $380 \mathrm{~V}$ through the PI controller. Detailed control operation of AC/DC converter and DC/DC converter is implemented using EMTP/MODELS. The proposed algorithm is implemented using MATLAB. The 120 samples/cycle are used.

Table 1 shows the simulation conditions. The faults at LVDC bus and LVDC line are simulated. Fault type is set as pole-to-pole fault. The fault resistances are 0.1 and $1 \mathrm{ohms}$. The fault occurred at $0.5 \mathrm{~s}$, and the fault duration is set as a permanent fault. In the simulation, $\alpha$ is set as 7000 . In the simulation results, ' 1 ' means the LVDC bus fault and ' 2 ' means the LVDC line fault.

Table 1. Simulation conditions in simple LVDC system.

\begin{tabular}{cccc}
\hline Cases & Fault Section & Fault Resistance $(\Omega)$ & $\begin{array}{c}\text { Fault Length on } \\
\text { Distribution Line }\end{array}$ \\
\hline Case 1 & LVDC Bus & 0.1 & - \\
Case 2 & LVDC Bus & 1 & $1 \mathrm{~km}$ \\
Case 3 & LVDC Line & 0.1 & $1 \mathrm{~km}$ \\
Case 4 & LVDC Line & 1 & $0.4 \mathrm{~km}$ \\
Case 5 & LVDC Line & 1 & $1.6 \mathrm{~km}$ \\
Case 6 & LVDC Line & 1 & \\
\hline
\end{tabular}

\subsubsection{Simulation Results}

Previous studies to judge the fault section have not been performed and hence this paper does not compare the simulation results with other methods. 
As representative simulation results, the currents flowing through the $\mathrm{CB}$ in cases 2 and 4 are presented in Figures 7 and 8. From Figure 7, it can be seen that the current flowing through the $C B$ after the fault which occurs at $0.5 \mathrm{~s}$ has a negative value. From Figure 8 , it can be seen that the current flowing through the $\mathrm{CB}$ after the fault occurrence maintains a positive value, so that the current of the same polarity as the normal state is maintained. These results are consistent with the theoretical analysis results in Section 2.

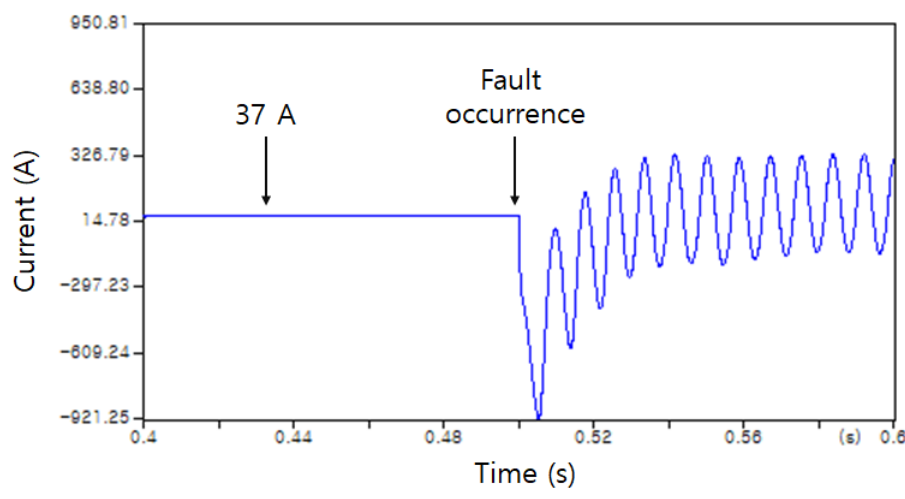

Figure 7. Current flowing through CB at case 2.

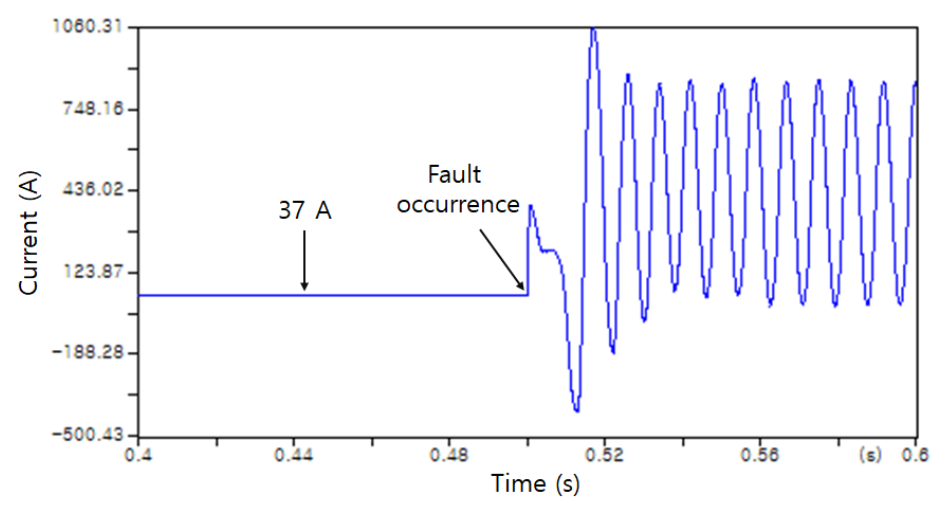

Figure 8. Current flowing through $\mathrm{CB}$ at case 4 .

Figures 9-14 show the calculation result of $I_{\text {wave }}$ by Equation (2) and the result of the fault section estimation accordingly in Cases 1-6. Figures 9 and 10 show the results at bus fault. From Figures $9 \mathrm{a}$ and $10 \mathrm{a}$, it can be seen that the calculation result of $I_{\text {wave }}$ is larger than the threshold value of 7000. Therefore, the simulation result of the fault section estimation presents the ' 1 ' as the bus fault by the proposed algorithm. Figures 10-14 show the results at the line faults. The various simulations according to the fault resistance and fault locations are performed. From each result, it can be seen that the calculation result of $I_{\text {wave }}$ shows a value of 4500 or less, which is smaller than the threshold value of 7000 . Therefore, it can be seen that the results of fault section estimation present ' 2 ' because it is determined as a line fault by the proposed algorithm. 


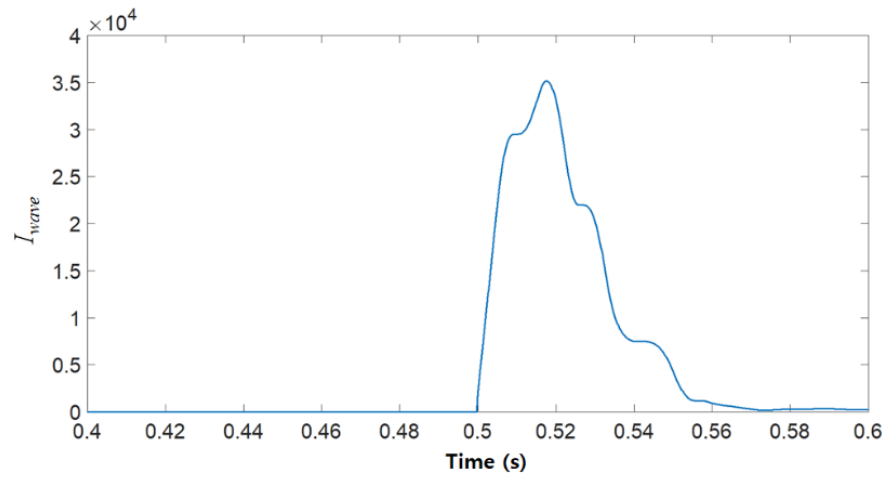

(a)

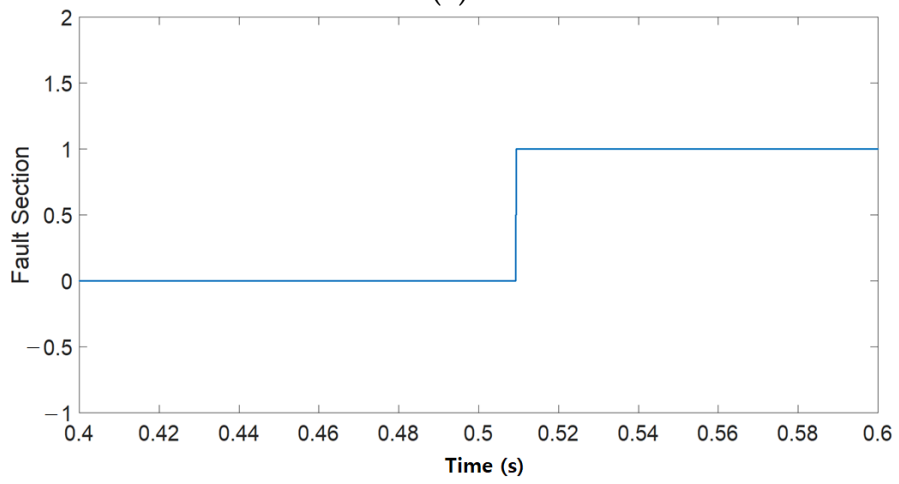

(b)

Figure 9. Simulation results of Case 1: (a) Calculation results of $I_{\text {wave }}$ (b) Fault section estimation.

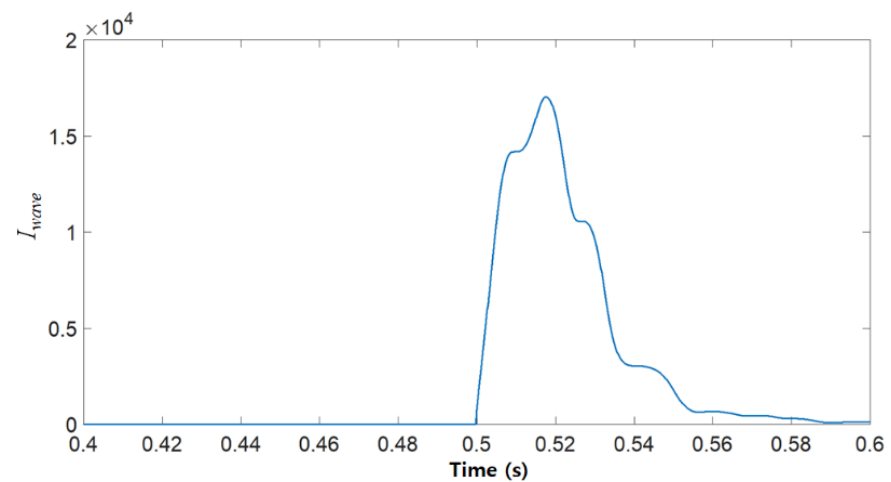

(a)

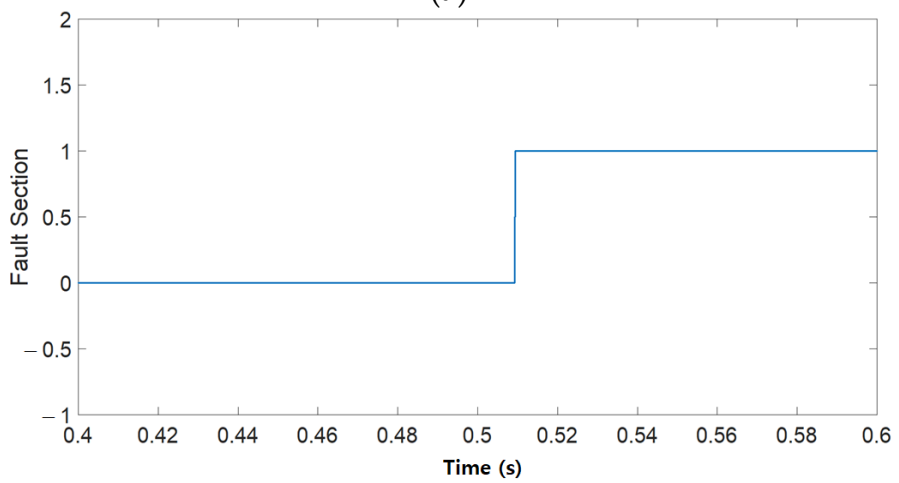

(b)

Figure 10. Simulation results of Case 2: (a) Calculation results of $I_{\text {wave }}$ (b) Fault section estimation. 


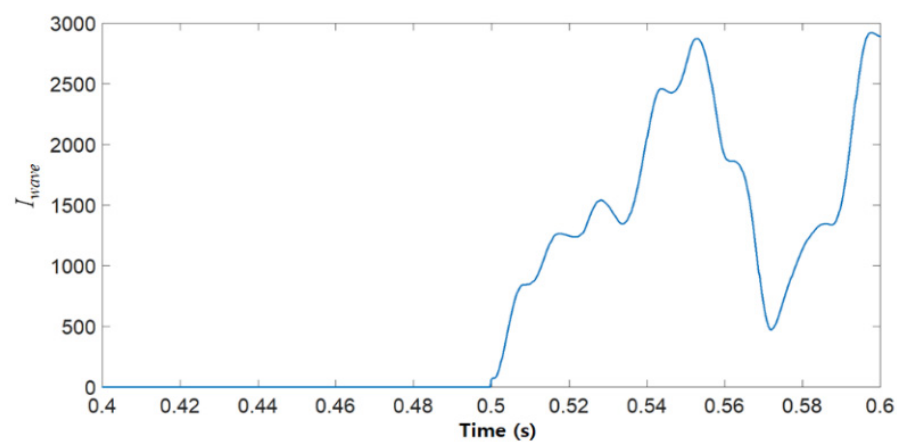

(a)

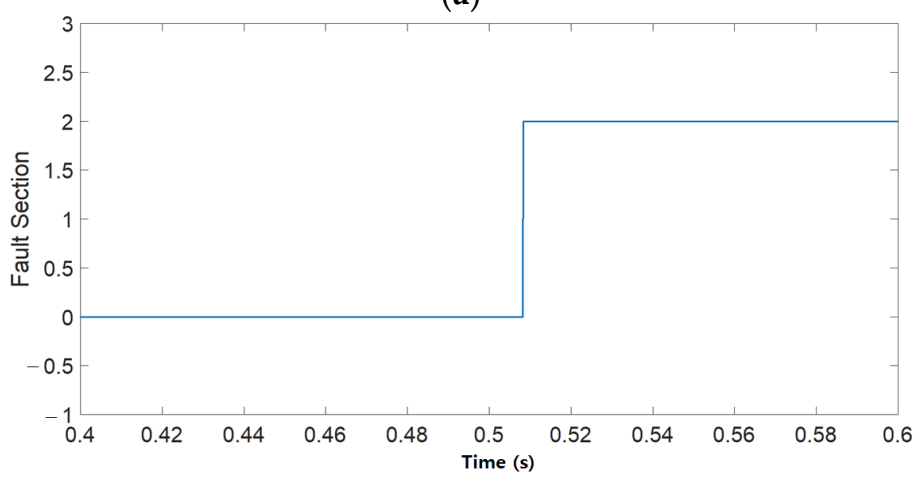

(b)

Figure 11. Simulation results of Case 3: (a) Calculation results of $I_{\text {wave }}$ (b) Fault section estimation.

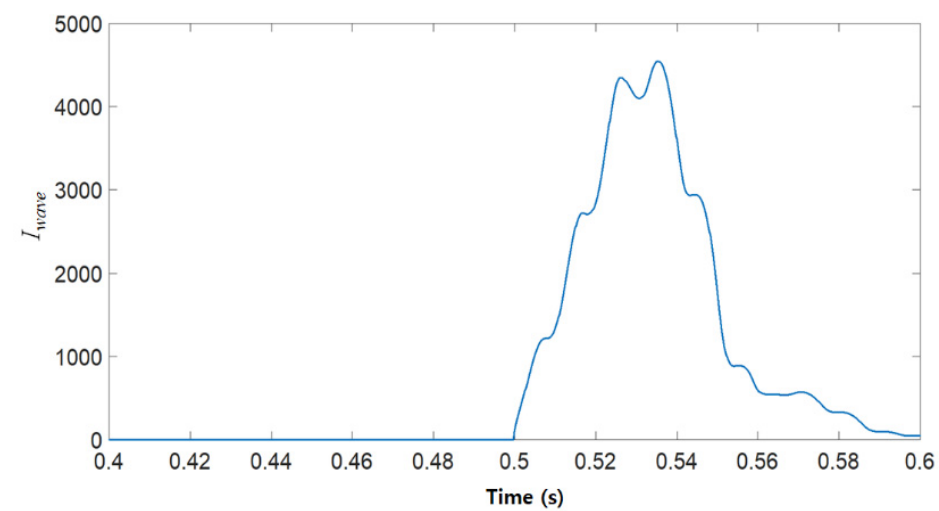

(a)

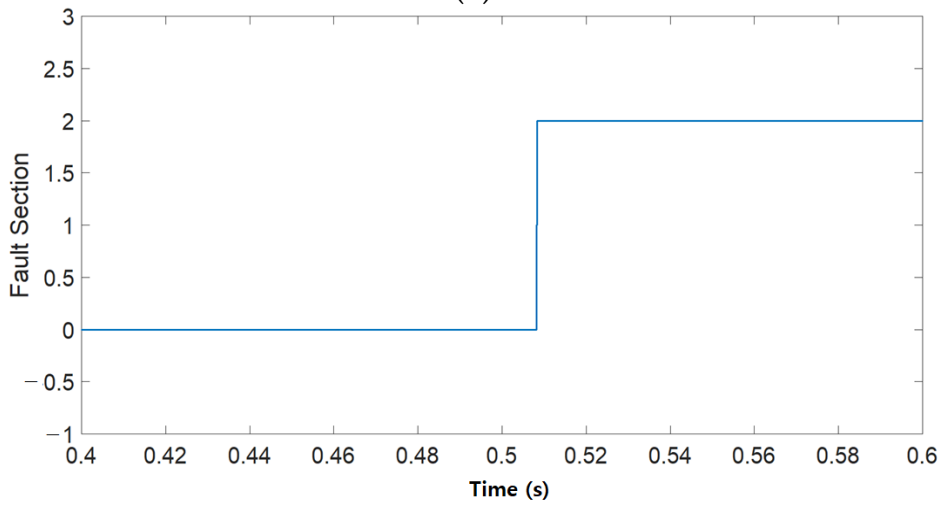

(b)

Figure 12. Simulation results of Case 4: (a) Calculation results of $I_{\text {wave }}$ (b) Fault section estimation. 


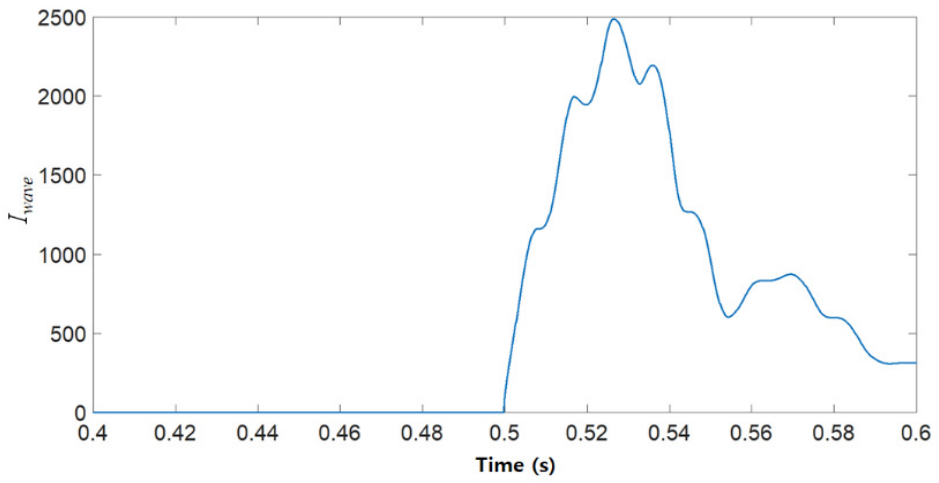

(a)

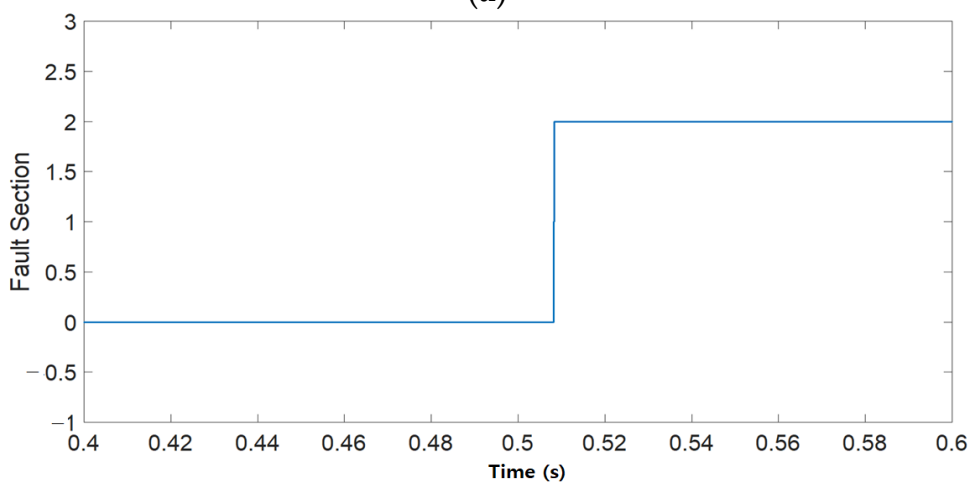

(b)

Figure 13. Simulation results of Case 5: (a) Calculation results of Iwave (b) Fault section estimation.

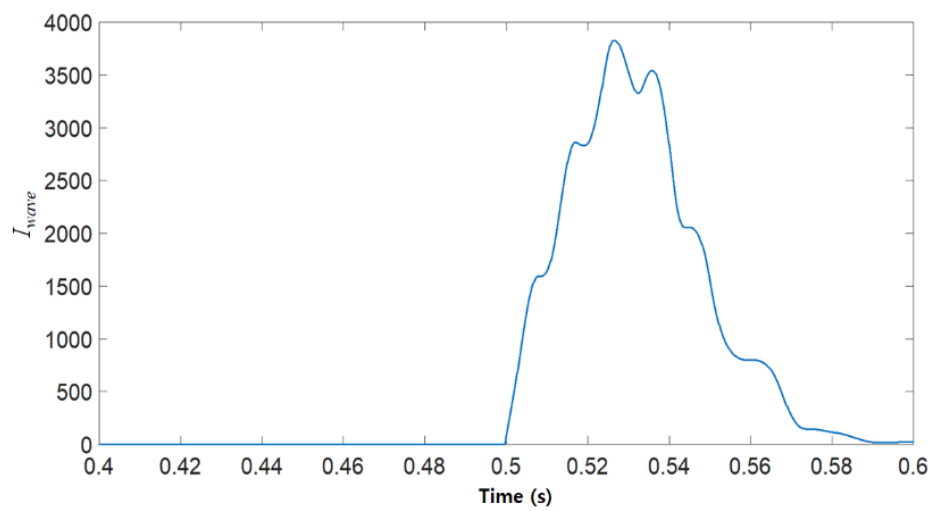

(a)

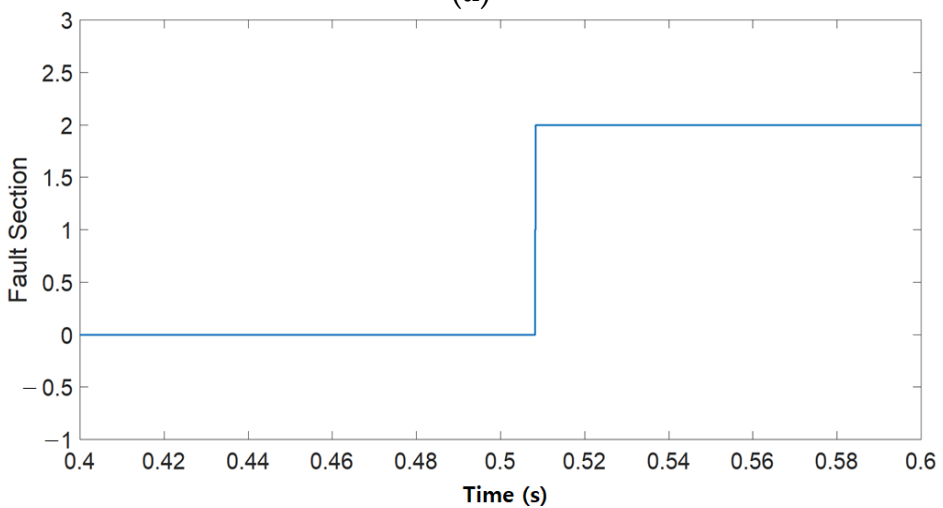

(b)

Figure 14. Simulation results of Case 6: (a) Calculation results of $I_{\text {wave }}$ (b) Fault section estimation. 


\subsection{Verification in Actual LVDC Distribution System}

\subsubsection{System Model and Simulation Conditions}

In Section 4.2, the proposed algorithm is verified in the actual complex LVDC distribution system. The actual complex LVDC distribution system consists of a number of distribution lines and loads, as shown in Figure 15.

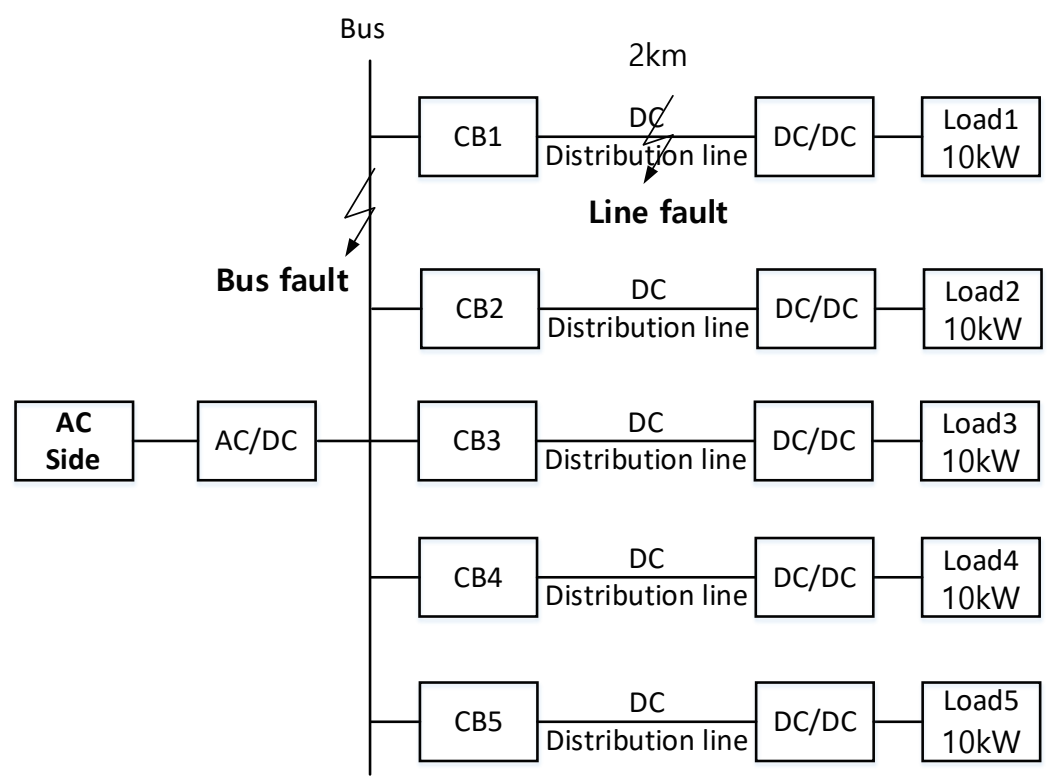

Figure 15. Actual LVDC distribution model.

In Figure 15, the length of each distribution line is $2 \mathrm{~km}$ and the total load capacity is $50 \mathrm{~kW}$. The pole-to-pole voltage at LVDC bus is $1500 \mathrm{~V}$ and the pole-to-pole voltage at load is $380 \mathrm{~V}$. This system model is modeled using EMTP as in the verification in Section 4.1. Figure 15 is also the ungrounded system. Similar with the modelling of Figure 1, the positive and negative poles in the EMTP modelling exist and the neutral line does not exist. The system modeling and the various simulations are performed using EMTP. The proposed algorithm is implemented using MATLAB. The current flowing through the CB is extracted from the simulation result of EMTP and converted into the input file for MATLAB. The calculation of $I_{\text {wave }}$ and fault area estimation are performed in MATLAB. Table 2 shows the simulation conditions in actual LVDC distribution system. The various simulations according to the fault section, fault resistance, and the fault length on the distribution line are performed. The fault type is pole-to-pole fault. The fault occurred at $0.5 \mathrm{~s}$, and the duration time of it is a permanent fault. The threshold value $\alpha$ in the proposed algorithm is 2500 . This value depends on the system configuration and the system parameters.

Table 2. Simulation conditions in actual LVDC system.

\begin{tabular}{cccc}
\hline Cases & Fault Section & Fault Resistance $(\Omega)$ & $\begin{array}{c}\text { Fault Length on } \\
\text { Distribution Line }\end{array}$ \\
\hline Case 7 & LVDC Bus & 0.1 & - \\
Case 8 & LVDC Bus & 1 & - \\
Case 9 & LVDC Line & 0.1 & $1 \mathrm{~km}$ \\
Case 10 & LVDC Line & 1 & $1 \mathrm{~km}$ \\
Case 11 & LVDC Line & 1 & $0.4 \mathrm{~km}$ \\
Case 12 & LVDC Line & 1 & $1.6 \mathrm{~km}$ \\
\hline
\end{tabular}

\subsubsection{Simulation Results}

Previous studies to judge the fault section have not been performed and hence this paper does not compare the simulation results with other methods. 
Figures 16 and 17 present the current flowing through the $\mathrm{CB}$ in the actual distribution system, which is a representative case of each fault section. Figure 16 is a case of bus fault; it can be seen that the (-) value is observed after the fault occurrence in $0.5 \mathrm{~s}$. Figure 17 shows the case of line fault; it can be seen that the $(+)$ value is observed after the fault occurrence. This is consistent with the analysis results in Section 2. In other cases, the change in fault current polarity is consistent with the results of the analysis in Section 2.

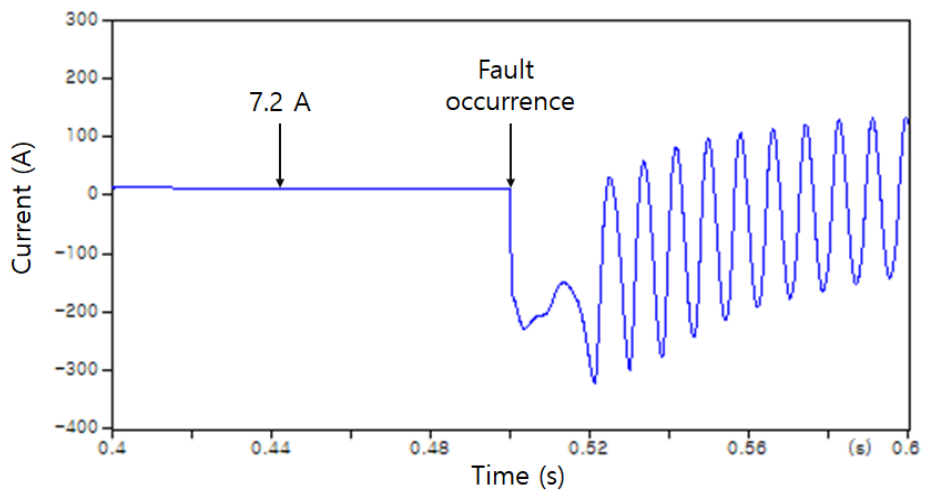

Figure 16. Current flowing through $\mathrm{CB}$ at case 8.

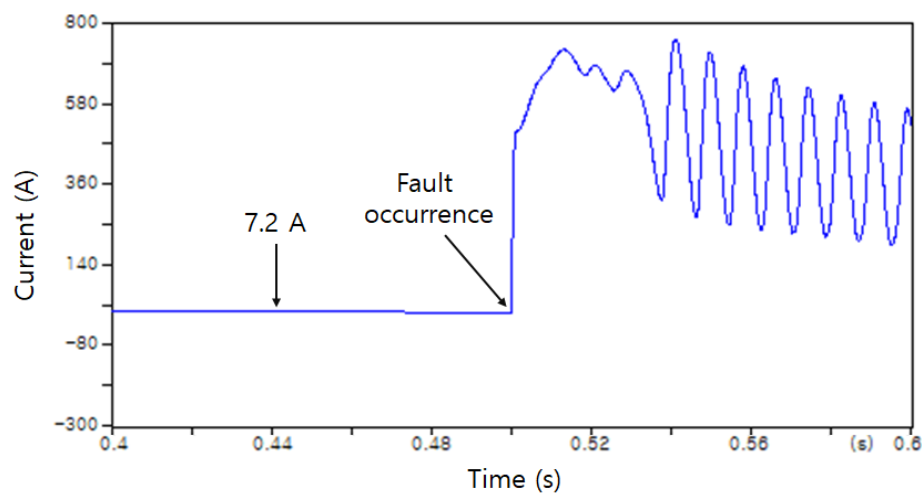

Figure 17. Current flowing through CB at case 10.

Figures 18-23 show the calculation results of $I_{\text {wave }}$ and the estimation result of the fault section at cases 7-12. Figures 18 and 19 show that the calculation results of $I_{\text {wave }}$ are larger than the threshold value of 2500. Therefore, according to the proposed algorithm, it is judged as a bus fault, and the result of fault section estimation presents ' 1 '. Figures 20-23 show that the calculation results of $I_{\text {wave }}$ are less than 2500 regardless of the fault resistance and fault length. Therefore, it can be seen that according to the proposed algorithm, it is judged as a line fault, and the result of fault section estimation presents ' 2 '. 


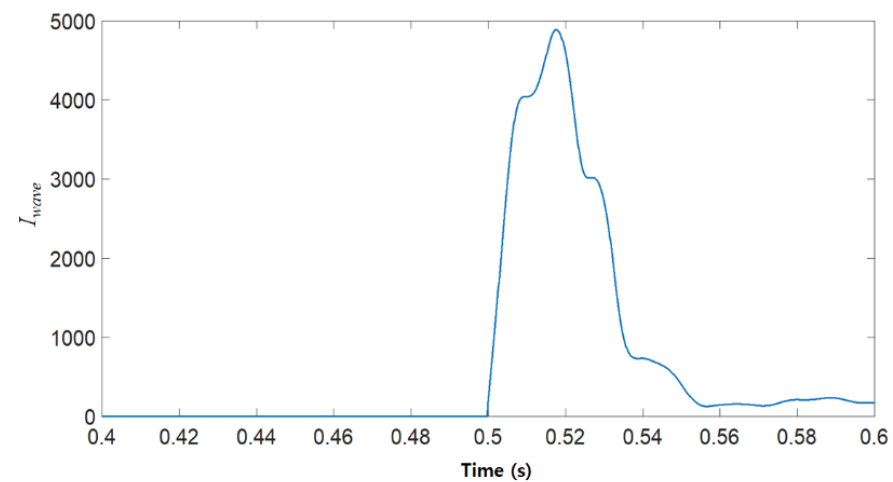

(a)

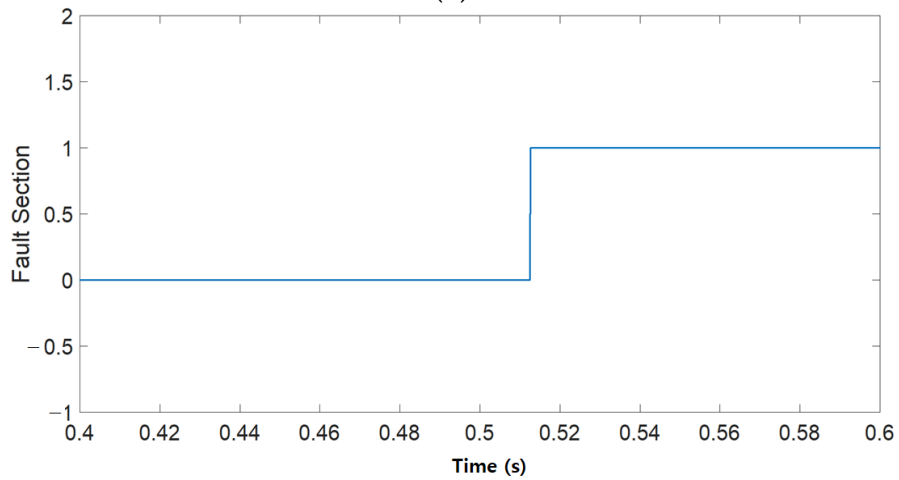

(b)

Figure 18. Simulation results of Case 7: (a) Calculation results of $I_{\text {wave }}$ (b) Fault section estimation.

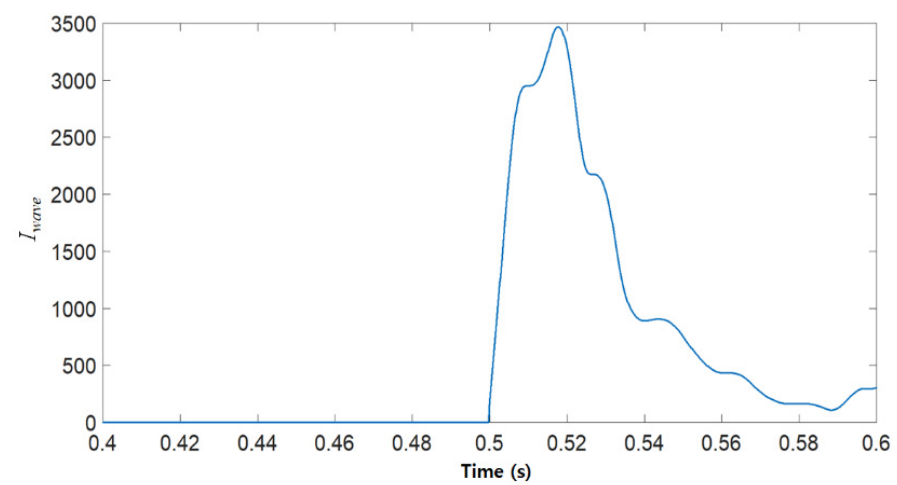

(a)

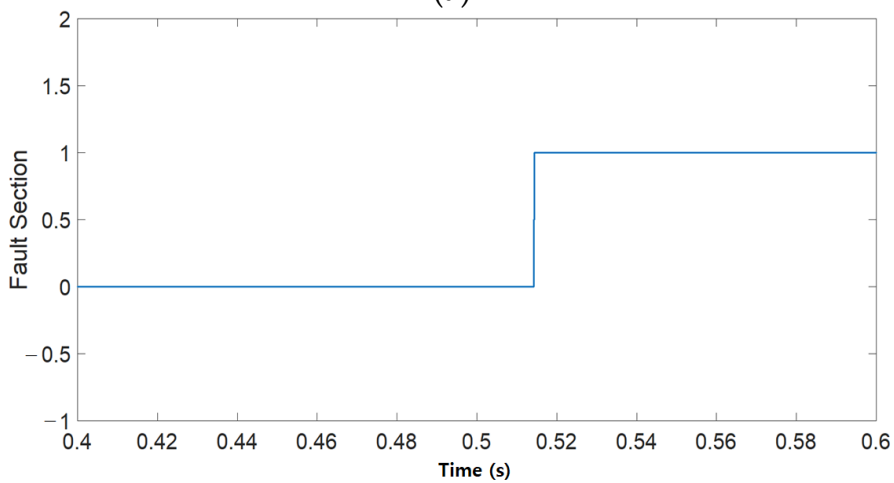

(b)

Figure 19. Simulation results of Case 8: (a) Calculation results of $I_{\text {wave }}$ (b) Fault section estimation. 


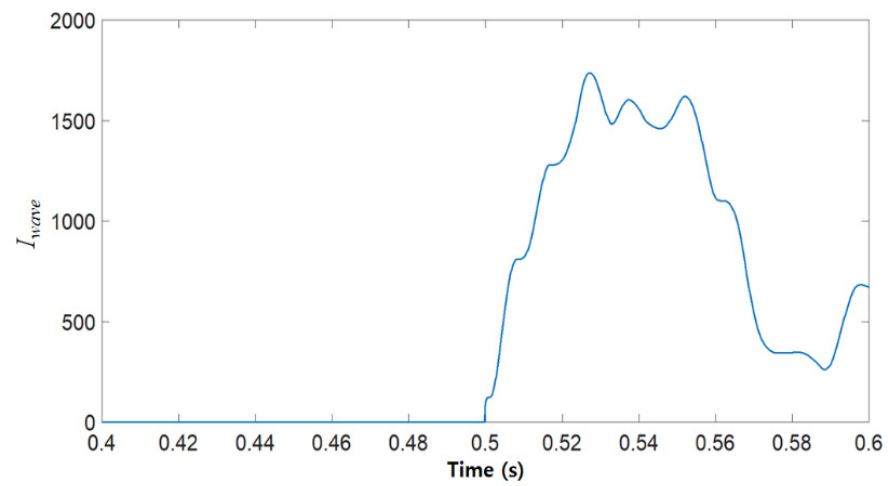

(a)

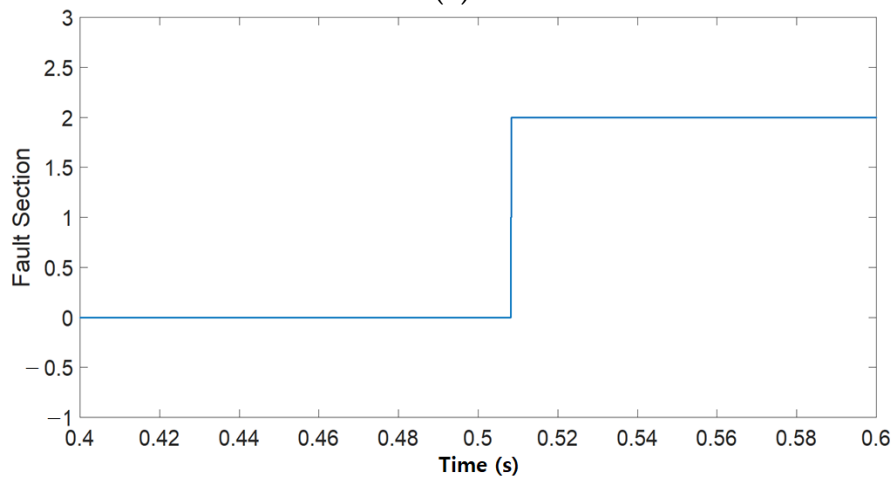

(b)

Figure 20. Simulation results of Case 9: (a) Calculation results of $I_{\text {wave }}$ (b) Fault section estimation.

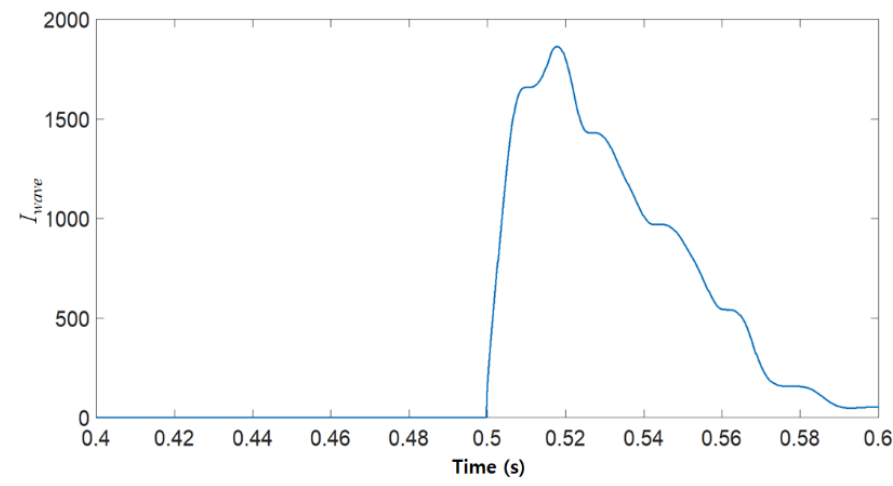

(a)

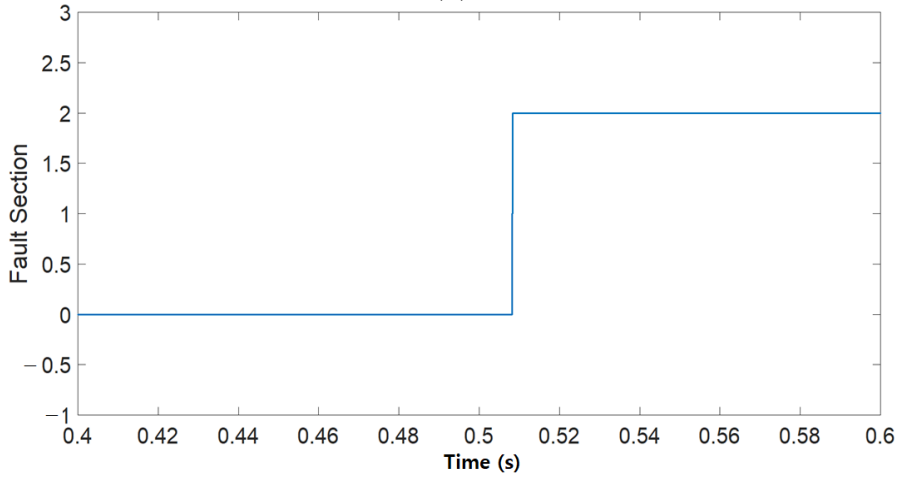

(b)

Figure 21. Simulation results of Case 10: (a) Calculation results of $I_{\text {wave }}$ (b) Fault section estimation. 


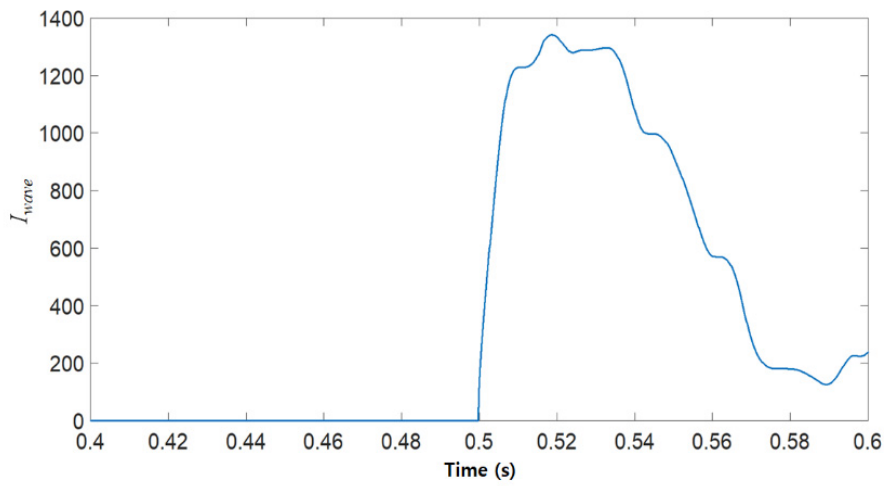

(a)

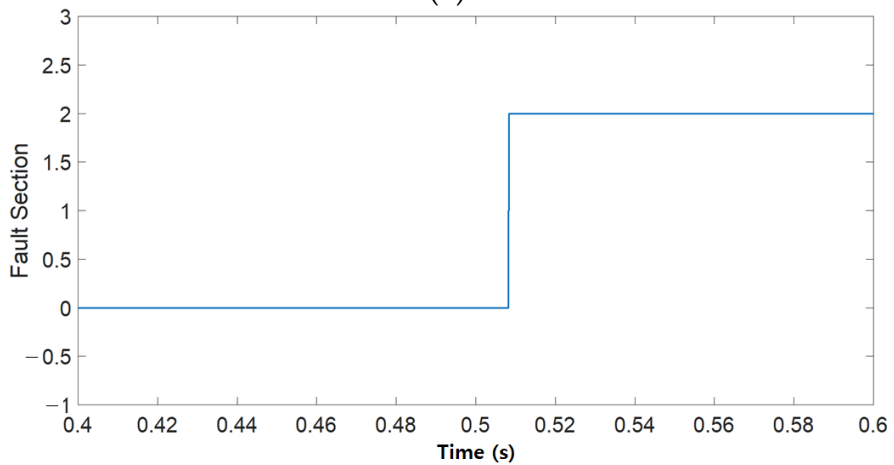

(b)

Figure 22. Simulation results of Case 11: (a) Calculation results of $I_{\text {wave }}$ (b) Fault section estimation.

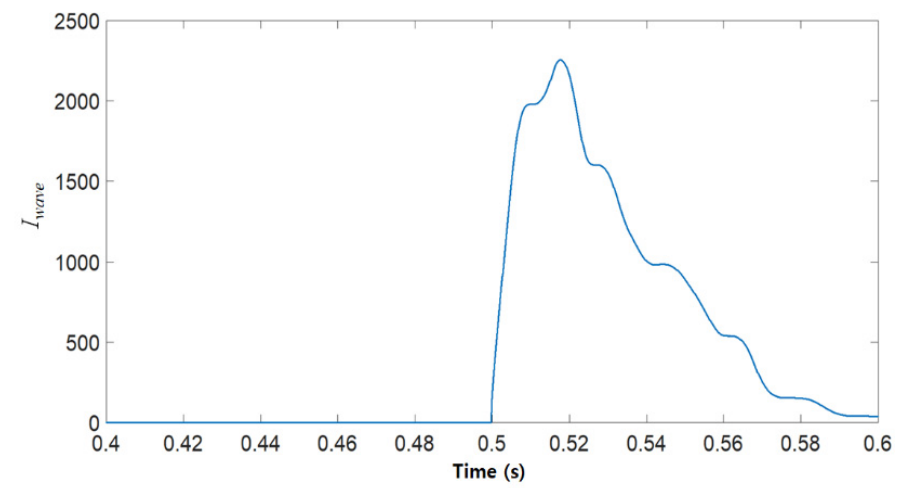

(a)

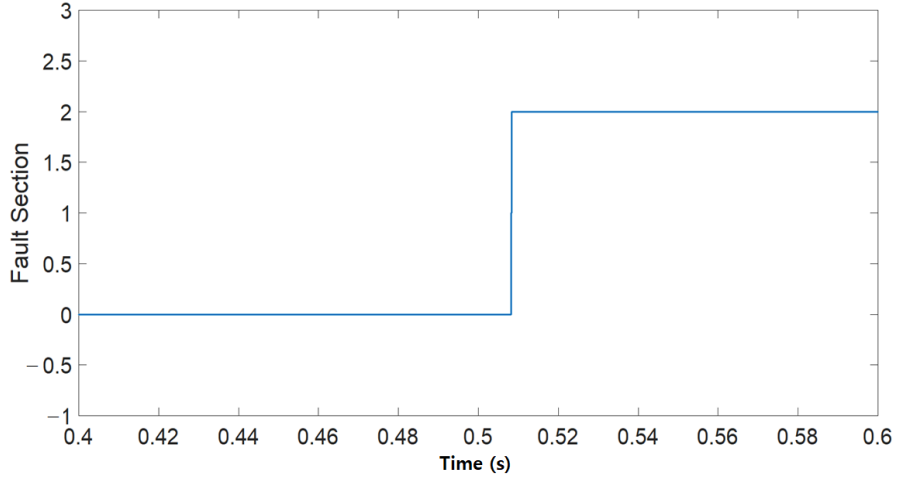

(b)

Figure 23. Simulation results of Case 12: (a) Calculation results of $I_{\text {wave }}$ (b) Fault section estimation. 


\section{Conclusions}

For the stable operation of the LVDC distribution system, it is necessary to estimate the fault section and apply the appropriate protection method. In this paper, the fault section estimation method using WT in LVDC distribution system was proposed. The characteristics of fault currents according to fault sections were analyzed in simple distribution systems and in actual complex distribution systems. Based on this analysis, the algorithm for fault section estimation using the WT was proposed. The proposed method receives the current flowing through the CB as an input and performs the WT of level 7. The mother wavelet is sym5. $I_{\text {wave }}$ of Equation (3) was calculated using detail components. Using $I_{\text {wave }}$, the proposed algorithm determined the fault section as LVDC bus fault or LVDC line fault.

The proposed method was verified through simulations using EMTP and MATLAB. The simple and actual complex LVDC distribution systems were modeled. The various simulations according to the fault section, fault resistance, and fault length were performed. The simulation results show that the proposed algorithm accurately estimates the fault section using $I_{\text {wave }}$ regardless of the fault resistance and fault length.

The proposed algorithm uses the 120 samples/cycle and does not require the use of large data. Therefore, the advantage of the proposed algorithm is that the hardware implementation is possible. Additionally, because the judgement of faulted line by applying the proposed algorithm in the actual LVDC distribution system will be possible, the isolation of faulted line will be also possible. Therefore, it is expected that the advantage of the power supply will be maintained in the non-faulted line. The disadvantage of the proposed algorithm does not include the judgement of the faulted line. To apply the proposed algorithm in the actual complex system, the judgement of the faulted line should be included; however, we have skipped this process in the algorithm.

As a future study, we will study the protection method including the judgement of faulted line in the actual complex LVDC distribution system based on the proposed algorithm.

Author Contributions: Conceptualization, H.-C.S. and G.-H.G.; methodology, H.-C.S.; software, H.-C.S. and G.-H.G.; validation, H.-C.S., G.-H.G. and K.-W.P.; writing-review and editing, H.-C.S., G.-H.G. and K.-W.P. All authors have read and agreed to the published version of the manuscript.

Funding: This research received no external funding.

Institutional Review Board Statement: Not applicable.

Informed Consent Statement: Not applicable.

Data Availability Statement: Not applicable.

Conflicts of Interest: The authors declare no conflict of interest.

\section{Nomenclature}

$\begin{array}{ll}x(n) & \text { Input signal } \\ g(n) & \text { Mother wavelet } \\ a_{0}^{m} & \text { Scale parameter } \\ n a_{0}^{m} b_{0} & \text { Time shift of } g(n) \\ b & \text { Translation parameter } \\ m & \text { Integer parameter } \\ S & \text { Original signal } \\ D 1, D 2, \ldots, D n: & \text { Detail components after WT } \\ A n & \text { Approximation component after WT } \\ T & \text { Period based on } 60 \mathrm{~Hz} \text { of AC } \\ i & \text { present sample } \\ I_{\text {wave }} & \text { Value to judge the fault section after WT }\end{array}$




\section{References}

1. Seo, H.C.; Gwon, G.H.; Park, K.W. Fault Section Estimation in LVDC Distribution System. In Proceedings of the APAP 2021 Conference, Jeju, Korea, 11-14 October 2021.

2. Emhemed, A.; Burt, G. An Advanced Protection Scheme for Enabling an LVDC Last Mile Distribution Network. IEEE Trans. Smart Grid 2014, 5, 2602-2609. [CrossRef]

3. Emhemed, A.A.S.; Fong, K.; Fletcher, S.; Burt, G.M. Validation of Fast and Selective Protection Scheme for an LVDC Distri-bution Network. IEEE Trans. Power Deliv. 2017, 32, 1432-1440. [CrossRef]

4. Oh, Y.-S.; Kim, C.-H.; Gwon, G.-H.; Noh, C.-H.; Bukhari, S.B.A.; Haider, R.; Gush, T. Fault detec-tion scheme based on mathematical morphology in last mile radial low voltage DC distribution networks. Int. J. Electr. Power Energy Syst. 2019, 106, 520-527. [CrossRef]

5. Wang, D.; Psaras, A.; Emhemed, A.A.; Burt, G.M. A novel fault let-through energy based fault location for LVDC dis-tribution networks. IEEE Trans. Power Deliv. 2020, 36, 966-974. [CrossRef]

6. Mohanty, R.; Balaji, U.S.M.; Pradhan, A.K. An Accurate Noniterative Fault-Location Technique for Low-Voltage DC Microgrid. IEEE Trans. Power Deliv. 2015, 31, 475-481. [CrossRef]

7. Feng, X.; Qi, L.; Pan, J. A Novel Fault Location Method and Algorithm for DC Distribution Protection. IEEE Trans. Ind. Appl. 2017, 53, 1834-1840. [CrossRef]

8. Jiang, S.; Fan, C.; Huang, N. Fault location in low-voltage direct current network based on auxiliary injection unit. IET Gener. Transm. Distrib. 2019, 13, 4347-4354. [CrossRef]

9. Abdali, A.; Mazlumi, K.; Noroozian, R. High-speed fault detection and location in DC microgrids systems using Mul-ti-Criterion System and neural network. Appl. Soft Comput. 2019, 79, 341-353. [CrossRef]

10. Xiao, Z.; Zheng, X.; Tai, N.; Gao, X. A novel probe-power based fault location method for LVDC microgrid using short time fourier transform. In Proceedings of the 16th IET International Conference on AC and DC Power Transmission (ACDC 2020), Online Conference, 2-3 July 2020.

11. Bhargav, R.; Bhalja, B.R.; Gupta, C.P. Novel Fault Detection and Localization Algorithm for Low-Voltage DC Microgrid. IEEE Trans. Ind. Inform. 2019, 16, 4498-4511. [CrossRef]

12. Xue, S.-M.; Liu, C. Line-to-Line Fault Analysis and Location in a VSC-Based Low-Voltage DC Distribution Network. Energies 2018, 11, 536. [CrossRef]

13. Jamali, S.Z.; Bukhari, S.B.A.; Khan, M.O.; Mehdi, M.; Noh, C.-H.; Gwon, G.-H.; Kim, C.-H. Protection Scheme of a Last Mile Active LVDC Distribution Network with Reclosing Option. Energies 2018, 11, 1093. [CrossRef]

14. Reddy, Y.O.; Chatterjee, S.; Chakraborty, A.K.; Bhowmik, A.R. Fault detection and location estimation for LVDC microgrid using self-parametric measurements. Int. Trans. Electr. Energy Syst. 2020, 30, e12499. [CrossRef]

15. Lee, K.-M.; Kim, J.-W.; Park, C.-W. Detection Method of Pole to Ground Fault in Ungrounded LVDC Distribution Grid Using DWT. J. Electr. Eng. Technol. 2019, 14, 1529-1536. [CrossRef]

16. Sharma, N.K.; Samantaray, S.R.; Bhende, C.N. VMD-Enabled Current-Based Fast Fault Detection Scheme for DC Microgrid. IEEE Syst. J. 2021, 1-12. [CrossRef]

17. Seo, H.-C. New Protection Scheme Based on Coordination with Tie Switch in an Open-Loop Microgrid. Energies 2019, $12,4756$. [CrossRef]

18. Seo, H.-C. Novel Protection Scheme considering Tie Switch Operation in an Open-Loop Distribution System using Wavelet Transform. Energies 2019, 12, 1725. [CrossRef]

19. Seo, H.-C.; Rhee, S.-B. Novel adaptive reclosing scheme using wavelet transform in distribution system with battery energy storage system. Int. J. Electr. Power Energy Syst. 2018, 97, 186-200. [CrossRef] 